Pesq. Vet. Bras. 30(5):453-464, maio 2010

\title{
Fatores de risco, achados clínicos, laboratoriais e avaliação terapêutica em 36 bovinos com deslocamento de abomaso ${ }^{1}$
}

\author{
Antônio Carlos Lopes Câmara ${ }^{2^{*}}$, José Augusto Bastos Afonso ${ }^{3}$, Nivaldo de \\ Azevêdo Costa $^{3}$, Carla Lopes de Mendonça ${ }^{3}$, Maria Isabel de Souza ${ }^{3}$ \\ e José Renato Junqueira Borges ${ }^{4}$
}

\begin{abstract}
Câmara A.C.L., Afonso J.A.B., Costa N.A., Mendonça C.L., Souza M.I. \& Borges J.R.J. 2010. [Risk factors, clinical and laboratorial findings and therapeutic evaluation in $\mathbf{3 6}$ cattle with abomasal displacement.] Fatores de risco, achados clínicos, laboratoriais e avaliação terapêutica em 36 bovinos com deslocamento de abomaso. Pesquisa Veterinária Brasileira 30(5):453-464. Programa de Pós-Graduação em Saúde Animal, Faculdade de Agronomia e Medicina Veterinária, Universidade de Brasília, 70636200 Brasília, DF, Brazil. E-mail: aclcamara@yahoo.com.br

The continuous genetic selection for high milk production in association with greater digestive capacity and corporal depth increases the susceptibility for abomasopathies including abomasal displacement. The present work aimed to accomplish a retrospective study on abomasal displacement in 36 cattle attended at Bovine Clinic, Garanhuns Campus, Federal Rural University of Pernambuco, through January 2000 to February 2009. Twenty seven cases of right abomasal displacement, six cases of left abomasal displacement and three of abomasal volvulus were diagnosed. Eleven moderate cases, without severe abdominal distention, appetite for roughage and metallic sound ("ping") reaching at the most the $8^{\text {th }}$ intercostal space were treated conservatively, and 20 severe cases with moderate to severe abdominal distention associated to systemic disturbances were treated surgically. Two cows were euthanized due to diffuse peritonitis or severe alterations in the abomasal serosa totalizing 18 animals submitted to the surgical treatment. Two animals were slaughtered and three cows arrived prostrated and died without receiving any treatment. Risk factor analysis identified rainy season as statistically significant. The greater number of abomasal displacement was in crossbred cows with 24 cases (66.6\%), followed by Holstein and Gir cattle with $11(30.5 \%)$ and one $(2.9 \%)$ cases, respectively. Food composition varied greatly and characterized by excess of carbohydrates and in most cases low quality fibers. Most frequent clinical signs were apathy, dehydration, light to severe ruminal bloat with reduced or absent motility, splashing sound during right flank ballottement, ping and a distended visceralike structure in the side of the displacement; liquid, blackish and fetid feces. Hematology reveals leukocytosis with neutrophilia and hyperfibrinogenemia in most cases. Ruminal fluid analysis showed compromised flora and fauna dynamics and increased chloride ion concentration in $93.9 \%$ of the cases achieving the media index of $47.66 \mathrm{mEq} / \mathrm{L}$. Clinical and surgical recovery rate achieved $100 \%$ and $72.2 \%$, respectively. Those methods described are viable options for the treatment of light and severe displacements but the prevention remains the best choice.
\end{abstract}

INDEX TERMS: Abomasopathies, clinical findings, hematology, risk factors, ruminal fluid analysis, pyloro-omentopexy.

\footnotetext{
${ }^{1}$ Recebido em 15 de setembro de 2009.

Aceito para publicação em 8 de janeiro de 2010.

Parte da dissertação de mestrado do primeiro autor.

2 Programa de Pós-Graduação em Saúde Animal, Faculdade de Agronomia e Medicina Veterinária (FAV), Universidade de Brasília (UNB), Galpão 4, Granja do Torto, Brasília, DF 70636-200, Brasil.

${ }^{*}$ Autor para correspondência: aclcamara@yahoo.com.br
}

\footnotetext{
${ }^{3}$ Clínica de Bovinos, Campus Garanhuns, Universidade Federal Rural de Pernambuco, Av. Bom Pastor s/n, Bairro Mundaú, Cx. Postal 152, Garanhuns, PE 55292-901, Brasil.

${ }^{4}$ Hospital Escola de Grandes Animais da Granja do Torto, Faculdade de Agronomia e Medicina Veterinária, Universidade de Brasília, Brasília, DF.
} 
RESUMO.- A contínua seleção genética para maior produção de leite em conjunto com o aumento da capacidade digestiva e profundidade corporal aumentou a susceptibilidade à ocorrência de abomasopatias, incluindo o deslocamento do abomaso. Este trabalho objetivou realizar um estudo retrospectivo sobre o deslocamento de abomaso em 36 bovinos atendidos na Clínica de Bovinos, Campus Garanhuns da Universidade Federal Rural de Pernambuco, durante o período de janeiro de 2000 a fevereiro de 2009. Foram diagnosticados 27 casos de deslocamento do abomaso à direita, seis casos de deslocamento do abomaso à esquerda e três casos de vólvulo abomasal. Onze casos considerados moderados, sem grave distensão abdominal, apetite presente para a forragem e delimitação de som metálico até o $8^{\circ}$ espaço intercostal, foram tratados clinicamente; enquanto 20 casos com distensão abdominal moderada a severa, associada a distúrbios sistêmicos, foram considerados graves e tratados cirurgicamente. Duas vacas foram eutanasiadas devido peritonite difusa ou alterações graves na serosa do abomaso, totalizando 18 animais submetidos ao tratamento cirúrgico. Dois animais foram encaminhados para abate e três vacas chegaram prostradas e morreram sem receber nenhum tratamento. A análise dos fatores de risco identificou a estação chuvosa como estatisticamente significativa. O maior número de deslocamento do abomaso ocorreu em vacas mestiças com 24 casos (66,6\%), seguida por bovinos da raça Holandesa com 11 (30,5\%) e Gir com um (2,9\%) caso. A composição da alimentação oferecida variou bastante e caracterizou-se por conter excesso de carboidratos e, na maioria dos casos, fibra de baixa qualidade. Os sinais clínicos mais frequentes foram comportamento apático, desidratação, timpanismo ruminal leve a severo com motilidade ausente ou diminuída, som de líquido ao balotamento do flanco direito, som de chapinhar metálico e/ou observação de uma estrutura similar a uma víscera distendida no gradil costal do lado correspondente ao deslocamento; fezes liquefeitas, enegrecidas e de odor fétido. Os achados hematológicos revelaram, na maioria dos casos, leucocitose neutrofílica e hiperfibrinogenemia. Na análise do fluido ruminal havia comprometimento da dinâmica da flora e fauna microbiana, e elevação no teor de cloreto em $93,9 \%$ dos casos, com o índice médio alcançando 47,66 mEq/L. O índice de recuperação clínica e cirúrgica alcançou $100 \%$ e $72,2 \%$, respectivamente. As condutas descritas são opções viáveis para o tratamento dos deslocamentos leves e severos, no entanto a prevenção permanece a melhor alternativa a ser adotada.

TERMOS DE INDEXAÇÃO: Abomasopatias, achados clínicos, análise do fluido ruminal, fatores de risco, hematologia, piloroomentopexia.

\section{INTRODUÇÃO}

As vacas leiteiras têm sofrido ao longo dos últimos anos constantes mudanças genéticas e de manejo com o intuito de maximizar a produção. A contínua seleção para maior produção de leite em conjunto com o aumento da capacidade digestiva e profundidade corporal aumentou a suscepti- bilidade de ocorrência de doenças metabólicas e digestivas, como as abomasopatias (Hansen 2000, Wittek et al. 2007).

No gado leiteiro, comumente as abomasopatias são associadas às doenças metabólicas, ao estresse lactacional e à insuficiência nutricional. As doenças do abomaso mais frequentes são: úlceras abomasais, compactação associada com indigestão vagal, compactação nutricional e deslocamento do abomaso (DA) (Radostits et al. 2007). Há, basicamente, duas possibilidades do deslocamento, na primeira a víscera migra de sua posição anatômica original, no assoalho do abdômen, para uma posição ectópica entre o rúmen e a parede abdominal esquerda, ocorrendo o deslocamento do abomaso à esquerda (DAE). Em uma segunda possibilidade, o órgão pode deslocar-se totalmente para o lado direito da cavidade abdominal provocando o deslocamento do abomaso à direita (DAD), que pode evoluir, em situações de maior risco, para o vólvulo abomasal (VA) (Barros Filho \& Borges 2007, Niehaus 2008).

Evidências de estudos epidemiológicos e experimentais nos últimos 50 anos identificaram grande variedade de fatores de riscos associados com a ocorrência do DA, entretanto a causa primária da enfermidade permanece desconhecida (Doll et al. 2009). Em 1961, Dirksen postulou que a desordem de motilidade abomasal (hipomotilidade ou atonia) ocorreria anterior à dilatação do órgão (Dirksen 1961). Esta hipótese vem sendo averiguada por diversos pesquisadores, e é relacionada, na maioria dos casos, à concentração elevada de carboidratos de fermentação rápida em relação à quantidade de fibra efetiva da dieta, principalmente no pós-parto (Coppock et al. 1972, Shaver 1997, Cameron et al. 1998, Stengärde \& Pehrson 2002, Doll et al. 2009).

A literatura mundial cita maior frequência do DAE sobre o DAD e VA, contribuindo com 85 a $95,8 \%$ de todos os casos (Sattler et al. 2000, Sexton et al. 2007). No Brasil, este padrão de casuística é mantido, existindo relatos no Estado de São Paulo, onde a relação de DAE e DAD é de 5:1 (Birgel et al. 1990), enquanto no Paraná tal relação aumenta para 8 a 9:1 (Reichert Netto 1992). Existem ainda relatos de DA em bovinos leiteiros em Pernambuco (Coutinho et al. 2002, Câmara et al. 2007, 2008), Goiás (Silva et al. 2004, 2008), Distrito Federal (Guimarães et al. 2007) e Rio Grande do Sul (Cardoso et al. 2008); enquanto em bovinos de corte, apenas no Distrito Federal (Câmara et al. 2009). Assim como outras doenças da produção (metrite, retenção de placenta, cetose, hipocalcemia, mastite, doença cística ovariana), o DA acarreta grande perda econômica na indústria leiteria e diminui o bem-estar animal (Ingvartsen et al. 2003, Mullingan \& Doherty 2008). No Brasil, os poucos estudos existentes quantificam apenas as perdas decorrentes do descarte de vacas leiteiras com a enfermidade (Silva et al. 2004, 2008). Entretanto, a casuística da Clínica de Bovinos, Campus Garanhuns da Universidade Federal Rural de Pernambuco (CBG-UFRPE) confirma o DA como uma importante doença digestiva e causa de cirurgia abdominal em bovinos leiteiros (Afonso 2005, Câmara et al. 2008). 
Com base na relevância desta enfermidade na bacia leiteira de Pernambuco, o presente trabalho teve como objetivo realizar um estudo retrospectivo a fim de identificar os principais fatores de risco e relatar os achados clínicos e laboratoriais em 36 bovinos com DA atendidos na CBGUFRPE no período de janeiro de 2000 a fevereiro de 2009, bem como avaliar a eficiência das condutas terapêuticas.

\section{MATERIAL E MÉTODOS}

O estudo retrospectivo sobre a ocorrência do DA foi realizado a partir da análise das fichas clínicas de 36 bovinos adultos (34 vacas e dois touros), oriundos de municípios pernambucanos e atendidos na CBG-UFRPE, no período de janeiro de 2000 a fevereiro de 2009.

Todos os animais foram examinados clinicamente seguindo as recomendações de Dirksen et al. (1993). Foram coletadas, através de venopunção jugular, amostras sanguíneas de 26 animais em tubo a vácuo com anticoagulante EDTA (10\%), para realização de hemograma e determinação da proteína plasmática e fibrinogênio plasmático segundo Jain (1993). Em todos os animais, amostras de fluido ruminal foram analisadas de acordo com Dirksen et al. (1993). Em 34 amostras foi realizada a dosagem do teor de cloretos, empregando-se kit comercial $^{5}$, sendo a leitura efetuada em analisador bioquímico semi-automático ${ }^{6}$. Em três bovinos, foi também realizado o teste de imunodifusão em gel de agarose (IDGA) para diagnóstico confirmatório da leucose enzoótica bovina (LEB) devido à linfocitose relativa e absoluta observada nos leucogramas.

Após o diagnóstico (Casos 1 a 6 com DAE; casos 7 a 33 com DAD e casos 34 a 36 com VA), quatro alternativas foram consideradas: 1) submeter os bovinos ao tratamento conservativo quando a condição clínica não representava risco de morte e este permanecia com apetite, sendo o quadro clínico considerado moderado; 2) submetê-los ao tratamento cirúrgico nos casos em que havia comprometimento sistêmico e distensão acentuada do abdômen, sendo considerados como graves; 3) realizar a eutanásia após laparotomia exploratória nos casos com serosa do abomaso friável e cianótica ou quadro clínico de peritonite difusa; 4) indicar os animais para abate por opção do proprietário após avaliação da relação custobenefício.

Nos casos diagnosticados como moderados foram realizadas fluidoterapia para correção do desequilíbrio hídricoeletrolítico, transfaunação com fluido ruminal de animais sadios (aproximadamente 10 litros/dia até o retorno da dinâmica digestiva), aplicação de soluções de cálcio diariamente, e tratamento de doenças concomitantes quando necessário. Nos casos graves realizou-se a laparotomia pelo flanco direito seguida de piloro-omentopexia de acordo com a técnica de Trent (2004) modificada. As modificações consistiram da utilização de fio de algodão "000" na piloro-omentopexia com ancoragem em uma segunda incisão (apenas pele) de $3 \mathrm{~cm}$ distando $5 \mathrm{~cm}$ da borda da incisão da laparotomia. Em alguns animais $(n=6)$ procedeuse também a exteriorização de parte do abomaso seguida de

\footnotetext{
${ }^{5}$ Cloretos ${ }^{\circledR}$, Labtest Diagnóstica SA, Avenida Paulo Ferreira 600, Lagoa Santa, Belo Horizonte, MG.

${ }^{6}$ Labquest $\circledast$, Bioplus Produtos para Laboratórios Ltda, Estrada Dr. Cícero Borges Morais 1581, Barueri, SP.

7 SPSS $\AA$ version 16.0. 2007. SPSS Incorporation, Chicago, Illinois, USA.
}

abomasotomia (incisão de aproximadamente $5 \mathrm{~cm}$ ) na curvatura maior do órgão devido ao grande acúmulo de líquido, com posterior massagem manual para retirada do conteúdo abomasal e sutura utilizando fio Categut cromado $\mathrm{n}^{01} \mathrm{em}$ dois planos com padrão Cushing. Os bovinos permaneceram internados para acompanhamento pós-operatório com instituição de terapia composta por antibióticos (oxitetraciclina LA; 20mg/ kg; via intramuscular; 72/72 horas; três aplicações) e antiinflamatórios não-esteroidais (fenilbutazona, $4 \mathrm{mg} / \mathrm{kg}$, via intramuscular, 24/24 horas, duas aplicações), além de terapia de suporte idêntica à instituída nos bovinos submetidos ao tratamento clínico. Durante o tempo de internação, a alimentação era à base de forragem de qualidade (capim elefante cortado em fibras de aproximadamente $10 \mathrm{~cm}$ de comprimento e Tifton) e água ad libitum. Os animais eram, também, estimulados ao exercício. Todos os bovinos que morreram ou foram eutanasiados durante o internamento foram necropsiados.

Nas propriedades dos bovinos acometidos pelo DA (propriedades caso) foram realizados questionários com o intuito de obter informações sobre as práticas de manejo da propriedade, a fim de identificar os possíveis fatores de risco existentes e comparar aos achados de outras propriedades (controle). As propriedades controle foram escolhidas no banco de dados da CBG-UFRPE, onde foram selecionadas aleatoriamente dentre àquelas que se situavam na mesma região fisiográfica da respectiva propriedade-caso e apresentavam semelhantes condições de manejo e características inerentes aos animais (raça, sexo, idade e produção leiteira), mas onde a enfermidade (DA) não foi diagnosticada, assim como recomendado por Schlesselman (1982). No estudo caso-controle realizou-se a análise univariada (teste qui-quadrado) dos possíveis fatores de risco, com intervalo de confiança de 95\% $(\mathrm{P}<0,05)$ (Schlesselman 1982), utilizando o programa estatístico SPSS $16.0^{7}$. As variáveis significativas foram submetidas à análise multivariada por regressão logística.

\section{RESULTADOS}

A análise univariada dos principais fatores de risco (sistema de criação, alimentação, raça, doenças concomitantes, estação do ano, produção leiteira e grau de tecnificação de manejo), onde todos os questionários foram realizados em fazendas consideradas caso e controle, indicou valor de $p$ significativo $(P<0,05)$ apenas para o quesito "estação do ano" ( $p=0,011)$, com a estação chuvosa sendo a de maior ocorrência de enfermidades (problemas de casco, tristeza parasitária, distocias, dentre outras). O resultado de apenas um fator apresentar-se estatisticamente significativo impossibilitou a utilização da análise multivariada associando a "estação do ano" com outro fator de risco também significativo.

Os dados epidemiológicos, evolução clínica, conduta terapêutica e desfecho dos casos estão resumidos no Quadro 1. A maioria dos bovinos era composta por vacas leiteiras adultas (34/36) criadas em sistema semi-intensivo, com livre acesso a alimentos volumosos no pasto, como capim Buffel (Cenchrus ciliaris), capim elefante (Pennisetum purpureum), capim Pangola (Digitaria decumbens) e/ou pastagem nativa. Os animais confinados recebiam toda a alimentação no cocho, como também 
Quadro 1. Dados epidemiológicos, evolução clínica, conduta terapêutica e desfecho em 36 bovinos com deslocamento do abomaso

\begin{tabular}{|c|c|c|c|c|c|c|c|c|c|c|c|c|c|c|}
\hline Bovino & Raça & $\begin{array}{l}\text { Idade } \\
\text { (anos) }\end{array}$ & Sexo & $\begin{array}{l}\text { Peso } \\
(\mathrm{kg})\end{array}$ & $\begin{array}{l}\text { Prenhez } \\
\text { (meses) }\end{array}$ & $\begin{array}{l}\text { Último } \\
\text { parto } \\
\text { (dias) }\end{array}$ & $\begin{array}{c}\text { Sistema } \\
\text { de criação }\end{array}$ & $\mathrm{DC}^{\mathrm{a}}$ & $\begin{array}{c}\text { Mês/es- } \\
\text { tação da } \\
\text { ocorrência }\end{array}$ & $\begin{array}{c}\text { Evolução } \\
\text { clínicab }^{\text {(dias) }}\end{array}$ & $\mathrm{DG}^{\mathrm{C}}$ & $\begin{array}{l}\text { Conduta } \\
\text { terapêutica }\end{array}$ & Desfecho & Município \\
\hline 1 & Mestiça & 6 & $\mathrm{~F}$ & 400 & Não & 180 & $\left.S\right|^{d}$ & Não & 12 / seca & $\mathrm{NI}^{\mathrm{e}}$ & $D A E^{f}$ & Clínica & Alta & Garanhuns \\
\hline 3 & Mestiça & 5 & $\mathrm{~F}$ & 490 & 5 & $\mathrm{NI}$ & SI & Leucose & 07 / chuva & 3 & $\mathrm{DAE}$ & Cirúrgica & Alta & Pedra \\
\hline 4 & $\mathrm{Hol}^{3}$ & 5 & $M$ & 680 & - & - & SI & Leucose & 04 / chuva & 30 & $\mathrm{DAE}$ & Clínica & Alta & Saloá \\
\hline 5 & Gir & $\mathrm{NI}$ & $\mathrm{M}$ & 510 & - & - & Intensivo & Não & 05 / chuva & 7 & DAE & Clínica & Alta & SBUg \\
\hline 8 & Mestiça & 6 & $\mathrm{~F}$ & 560 & 6 & 240 & SI & Não & 04 / chuva & 2 & DAD & Cirúrgica & Alta & Pedra \\
\hline 9 & $\mathrm{Hol}$ & 4 & $\mathrm{~F}$ & $\mathrm{NI}^{f}$ & Não & 360 & SI & Não & 01 / seca & 8 & DAD & - & Abate & Caruaru \\
\hline 10 & Mestiça & 4 & $\mathrm{~F}$ & 258 & Não & 60 & SI & Metrite & 03 / chuva & 3 & DAD & Cirúrgica & Alta & SBU \\
\hline 11 & Mestiça & 6 & $\mathrm{~F}$ & 450 & 5 & 210 & SI & Não & 06 / chuva & $\mathrm{NI}$ & DAD & Cirúrgica & Alta & Venturosa \\
\hline 12 & $\mathrm{Hol}^{3}$ & 5 & $\mathrm{~F}$ & 500 & Não & 12 & Intensivo & Metrite & 08 / chuva & 9 & DAD & Clínica & Alta & SBU \\
\hline 13 & Mestica & 6 & $\mathrm{~F}$ & $\mathrm{NI}$ & Não & 24 & SI & Metrite & 09 / seca & 2 & DAD & Clínica & Alta & Pedra \\
\hline 14 & Mestiça & 4 & $\mathrm{~F}$ & 400 & Não & 60 & SI & Não & 04 / chuva & 3 & DAD & Cirúrgica & Alta & Pedra \\
\hline 19 & Mestiça & 5 & $\mathrm{~F}$ & 400 & Não & 5 & SI & Não & 12 / seca & 5 & DAD & Cirúrgica & Óbito & Pedra \\
\hline 20 & Mestiça & 8 & $\mathrm{~F}$ & $\mathrm{NI}$ & Não & 300 & SI & Mastite & 01 / seca & 6 & DAD & Clínica & Alta & Pedra \\
\hline 21 & Mestiça & 3 & $\mathrm{~F}$ & 458 & Não & 60 & SI & Não & 03 / chuva & 3 & DAD & Clínica & Alta & Pedra \\
\hline 22 & Mestiça & 7 & $\mathrm{~F}$ & $\mathrm{NI}$ & $>8$ & $\mathrm{NI}$ & SI & Mastite & 04 / chuva & 3 & DAD & Clínica & Alta & Pedra \\
\hline 23 & $\mathrm{Hol}^{3}$ & 5 & $\mathrm{~F}$ & 539 & 2 & 160 & Intensivo & Mastite & 01 / seca & 4 & DAD & Cirúrgica & Alta & Venturosa \\
\hline 24 & Mestiça & 4 & $\mathrm{~F}$ & 310 & Não & 10 & $\mathrm{SI}^{\mathrm{d}}$ & Não & 12 / seca & 2 & DAD & Cirúr & Alta & Lajedo \\
\hline 25 & Mestiça & 8 & $\mathrm{~F}$ & 400 & $\Lambda$ & 168 & SI & $\mathrm{N}$ & 01 / seca & 4 & DAD & Cirúrgica & Óbito & Jurema \\
\hline 26 & $\mathrm{Hol}$ & $\mathrm{NI}$ & $\mathrm{F}$ & $\mathrm{NI}$ & Não & $\mathrm{NI}$ & SI & Não & 02 / seca & $\mathrm{NI}$ & DAD & Cirúrgica & Eutanásia & Pedra \\
\hline 27 & Mestiça & 5 & $\mathrm{~F}$ & 458 & Não & 90 & Intensivo & Não & 02 / seca & 9 & DAD & Cirúrgica & Óbito & Pedra \\
\hline 28 & $\mathrm{Hol}$ & 6 & $\mathrm{~F}$ & 495 & Não & 164 & SI & Não & 04 / chuva & 3 & DAD & Cirúrgica & Alta & Venturosa \\
\hline 29 & $\mathrm{Hol}$ & 6 & $\mathrm{~F}$ & $\mathrm{NI}$ & Não & 60 & SI & Não & 09 / seca & 8 & DAD & Clínica & Alta & Pedra \\
\hline 30 & Mestiça & 5 & $\mathrm{~F}$ & 390 & Não & 60 & SI & Não & 02 / seca & 3 & DAD & Cirúrgica & Alta & Lajedo \\
\hline 31 & Mestiça & 6 & $\mathrm{~F}$ & 410 & 2 & 155 & Intensivo & Não & 08 / chuva & 2 & DAD & Clínica & Alta & Pedra \\
\hline
\end{tabular}

a Doença concomitante, ${ }^{b}$ Dias após o início dos sinais clínicos observados pelos proprietários ou tratadores até o atendimento na CBG-UFRPE,

c Diagnóstico clínico, d Semi-intensivo, e Não informado, ${ }^{\dagger}$ Deslocamento do abomaso à esquerda, g São Bento do Una, hDeslocamento do abomaso à direita, ${ }^{\mathrm{i}}$ Vólvulo abomasal. $\mathrm{F}=$ fêmea, $\mathrm{M}=$ macho, $\mathrm{Hol}=$ Holandesa.

ocorria na suplementação oferecida aos bovinos do sistema de criação semi-intensivo, que consistia da mistura de diversos alimentos, dentre eles: palma forrageira (Opuntia ficus indica), capim elefante triturado, folhas de mandioca (Manihot spp.), casca de mandioca triturada, silagem de capim elefante, silagem de milho e sorgo, caroço de algodão, cama de frango, cevada, palha de milho e bagaço de cana (Sacharum spp.). A oferta de suplementação protéica (ração concentrada comercial ou formulada na própria fazenda, onde a constituição variava desde o simples farelo de milho ou soja até a mistura de farelo de milho, soja, caroço de algodão e/ou trigo) foi observada em 97,2\% (35/ 36) dos casos e a quantidade ofertada variou de 2 a $10 \mathrm{~kg} /$ animal/dia.

Após o diagnóstico clínico, as ectopias do abomaso observadas foram o DAD em 30 casos $(83,3 \%)$ e o DAE $(26,4 \%)$ em seis casos. O diagnóstico de VA foi confirma- do através da laparotomia exploratória pelo flanco direito (Bovino 35) e achados de necropsia (Bovinos 34 e 36). Deste modo, a casuística apresentou frequência de $75 \%$ (27/36) para o DAD; $16,7 \%$ (6/36) para o DAE; e 8,3\% (3/ 36) para o VA. O maior número de casos de DA ocorreu em bovinos mestiços (Holandesa x Gir) com 24 casos $(66,6 \%)$, seguido por animais da raça Holandesa com 11 casos $(30,5 \%)$ e a raça Gir com um caso $(2,9 \%)$.

Onze casos (4 DAE e 7 DAD) foram considerados moderados devido à ausência de distensão abdominal grave associada à presença de apetite e delimitação de som de chapinhar alcançando no máximo o $8^{\circ}$ espaço intercostal, sendo tratados conservativamente, enquanto 20 casos (2 DAE, 17 DAD e 1 VA) com moderada a severa distensão abdominal associada à distúrbios sistêmicos foram considerados graves e tratados cirurgicamente, dos quais dois animais (Bovinos 18 e 26) foram eutanasiados durante a laparotomia 


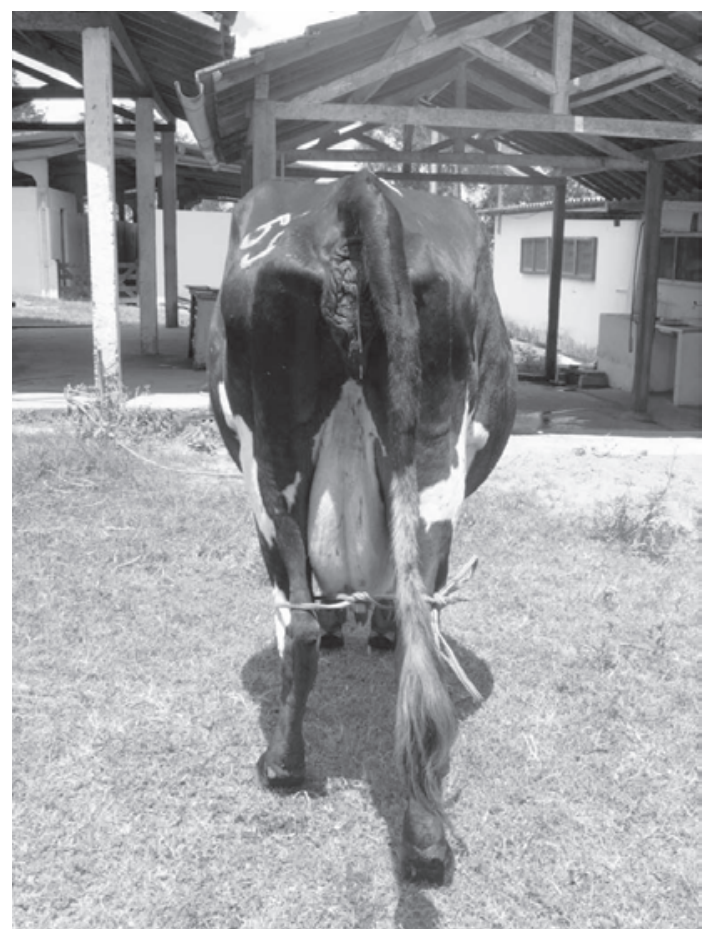

Fig.1. Abaulamento bilateral do abdômen do Bovino $28 \mathrm{com}$ deslocamento do abomaso à direita, mais evidente no antímero ventral direito.

exploratória devido peritonite difusa e/ou alterações graves na serosa do abomaso, totalizando 18 casos cirúrgicos. Dois casos (Bovinos 7 e 9) foram encaminhados para abate por opção do proprietário após avaliação da relação custo-benefício. Três vacas (Bovinos 33, 34 e 36) chegaram prostradas e morreram em até oito horas, sem receber nenhum tipo de tratamento.

Os casos de DA apresentaram a seguinte distribuição durante as estações no período estudado: 20 casos (55,5\%) na estação seca (meados de setembro a fevereiro) e 16 casos $(44,5 \%)$ na estação chuvosa (março a agosto).

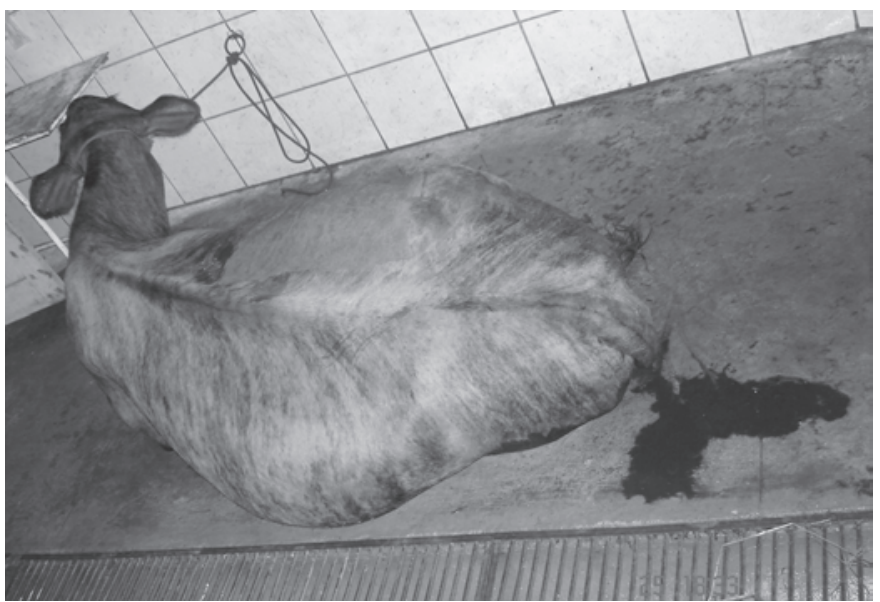

Fig.2. Bovino 22 com deslocamento do abomaso à direita apresentando fezes escassas, liquefeitas, enegrecidas e com odor fétido.
Os principais sinais clínicos observados e relatados pelos proprietários foram diminuição gradativa ou abrupta do apetite, queda da produção leiteira, cólicas com o ato de escoicear o abdômen, timpanismo leve a severo, fezes liquefeitas e enegrecidas, ou ausentes. A evolução clínica variou entre 3 e $30(13,6 \pm 0,40) ; 2-15(4,84 \pm 3,11)$ e 4-8 $(5,6 \pm 2,08)$ dias no DAE, DAD e VA, respectivamente.

Ao exame clínico, os sinais mais observados eram: comportamento apático, com diferentes níveis de indiferença aos estímulos externos; graus variados de desidratação, taquicardia, dispnéia inspiratória associada à taquipnéia devido à compressão diafragmática, timpanismo ruminal leve a severo com motilidade ausente ou diminuída, estratificações do rúmen ausentes ou com aumento do estrato gasoso, distensão abdominal uni ou bilateral (Fig.1), hipomotilidade intestinal, fezes liquefeitas, enegrecidas e de odor fétido (Fig.2), escassas ou ausentes com presença de muco. O achado clínico de maior importância no diagnóstico do DA foi a presença de área com som de chapinhar metálico, durante a auscultação e percussão, no flanco esquerdo (5/6) e flanco direito (27/30) que variava desde o $8^{\circ}$ espaço intercostal até a fossa paralombar (Fig.3); presença de som de líquido no balotamento (su-



Fig.3. Delimitação de área com som de chapinhar metálico ultrapassando a última costela em vacas com deslocamento do abomaso à direita, (A) Bovino 11, (B) Bovino 30. 
Quadro 2. Resultados do exame clínico em 36 bovinos com deslocamento do abomaso

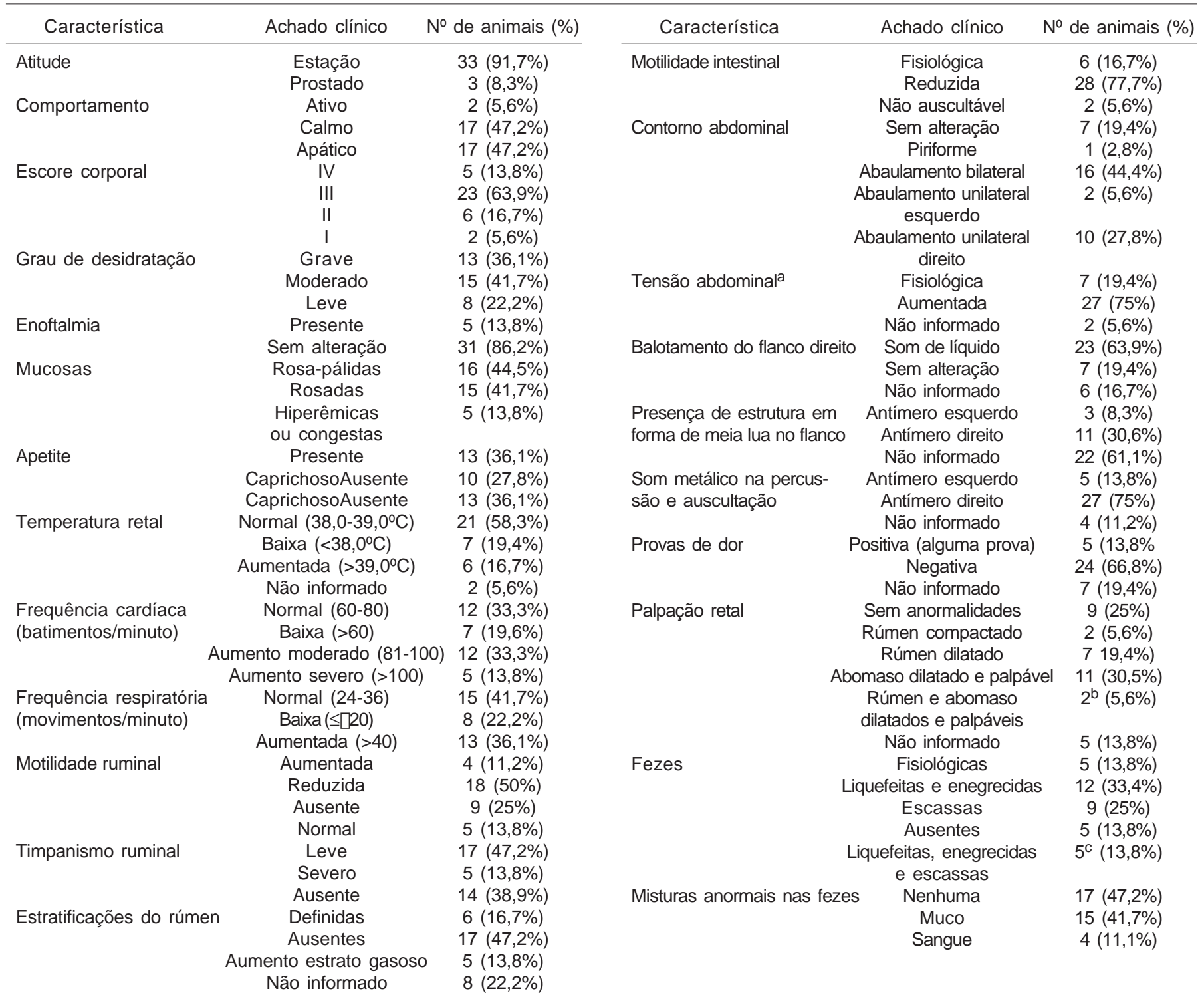

a Parâmetro influenciado nos três bovinos no trimestre final de gestação (Bovinos 8, 17 e 22), b Bovinos 20 e 30, c Bovinos 11, $16,18,22$ e 29.

cussão) do flanco direito, e constatação de estrutura similar a uma víscera distendida com formato de meia lua (Fig.4) no antímero correspondente ao lado do deslocamento (14/ 36). Através da palpação retal foi possível alcançar o abomaso distendido em 13 casos $(36,1 \%)$, apenas em animais com DAD ou VA (Bovino 35). Os resultados dos exames clínicos são apresentados no Quadro 2.

No presente estudo, 20 das 34 vacas $(58,8 \%)$ apresentaram-se acima das seis semanas (42 dias) pós-parto, enquanto $23,5 \%(8 / 34)$ encontravam-se no primeiro mês de parição e em 17,7\% (6/34) não se dispunha de tal dado. O diagnóstico de gestação revelou que sete $(20,5 \%)$ vacas apresentavam-se prenhes com período gestacional no segundo (2/7), quinto (1/7), sexto (2/7) e acima do oitavo mês $(2 / 7)$. Observou-se a presença de doenças concomitantes em 66,6\% (4/6) dos bovinos com DAE;
$34,6 \%(9 / 26)$ das vacas com DAD e $33,3 \%$ (1/3) dos casos de VA, sendo as enfermidades mais frequentes: metrite (5/14), mastite (4/14), LEB (3/14), pneumonia (1/14) e timpanismo espumoso (1/14) (Quadro 1).

Os achados hematológicos, da proteína plasmática total e do fibrinogênio plasmático revelaram que as alterações mais comuns nos animais com DAE consistiram de leucocitose $(21741 \pm 10310$ leucócitos $/ \mu L)$ por linfocitose $(13932 \pm 8383 / \mu \mathrm{L})$ observada em quatro de seis pacientes $(66,7 \%)$, enquanto em bovinos com DAD a leucocitose (17395 \pm 8551 leucócitos/ $\mu \mathrm{L})$ por neutrofilia (10192 \pm 5120 neutrófilos $/ \mu \mathrm{L}$ ) com desvio à esquerda regenerativo, e inversão da relação neutrófilos:linfócitos, foi o achado mais comum. No grupo diagnosticado com VA, a presença de neutrófilos imaturos (bastonetes) foi frequente, principalmente em uma vaca (Bovino 34), que apresentou o número de 


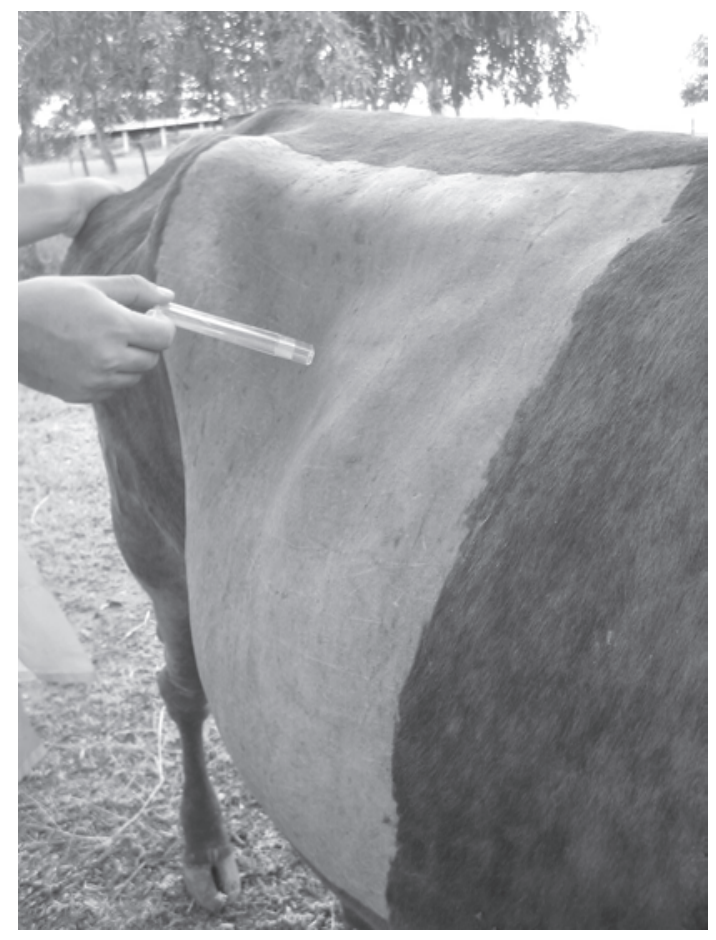

Fig.4. Fossa paralombar direita do Bovino 22 após tricotomia. É evidenciada estrutura similar a uma víscera distendida em formato de meia-lua.

bastonetes superior ao de neutrófilos segmentados, enquanto no Bovino 36 evidenciou-se o quadro de leucocitose por neutrofilia com desvio à esquerda regenerativo. A hiperfibrinogenemia (>700mg/dL), observada em 11 dos 26 bovinos $(42,3 \%)$, foi um achado comum nos três grupos (DAE, DAD e VA). Alguns animais apresentaram hiperproteinemia associada ao leve aumento do valor do hematócrito (2/36), enquanto outros revelaram discreta a acentuada hipoproteinemia (8/36). Os demais parâmetros encontravam-se dentro dos limites fisiológicos para a espécie (Kramer 2000). Os animais submetidos ao teste de IDGA (Bovinos 3, 4 e 6) resultaram positivos para LEB.

Com relação à análise do fluido ruminal e dosagem do teor de cloretos, as amostras analisadas apresentaram coloração que variou do castanho esverdeado (16/36), castanho (10/36), verde-oliva (5/36), castanho-escuro (3/36) a verde leitoso (2/36). O odor aromático, alterado (odor insípido indiferente) e fétido foi observado em 14, 20 e dois casos, respectivamente. A consistência do fluído ruminal variou de aquosa (6/36), levemente viscosa (22/36), viscosa (7/36) a espumosa (1/36), enquanto o valor médio do $\mathrm{pH}$ foi $7,6 \pm 0,4$. O tempo da prova de redução do azul de metileno apresentou-se elevado (8,8 $\pm 4,3$ minutos), enquanto a atividade dos protozoários encontrava-se comprometida (24,9 $\pm 20,5 \%$ vivos). O teor de cloretos no fluido ruminal apresentava-se elevado ( $>30 \mathrm{mEq} / \mathrm{L}$ ) em todos os casos de DAE (6/6) e VA (3/3), enquanto em $88 \%$ (22/25) dos bovinos com DAD constatou-se a mesma alteração, totalizando 31 de 34 casos (93,9\%), onde o índice médio alcançou 47,66 mEq/L.
O índice de recuperação total foi de $82,7 \%$ (24/29), pois os animais eutanasiados $(n=2)$, encaminhados para abate $(n=2)$ e que não receberam tratamento $(n=3)$ não foram incluídos no cálculo. O tratamento clínico apresentou índice de sobrevivência de 100\% (11/11) para ambos os deslocamentos, enquanto a eficácia do tratamento cirúrgico alcançou 100\% (2/2) em bovinos com DAE; 73,3\% (11/15) nos casos de DAD e zero (0/1) no VA. Dentre os animais com DAD, em seis casos cirúrgicos (Bovinos 8, 10, 15, 17,19 e 32) foi realizada a abomasotomia para retirada do líquido acumulado de coloração enegrecida e odor fétido (entre 8 e 35L), anterior a piloro-omentopexia, sendo obtida a recuperação clínica de quatro vacas, alcançando nestes animais o índice de $66,7 \%$.

Os dez animais que foram submetidos à necropsia apresentaram alterações semelhantes que consistiram de moderada quantidade de líquido peritoneal de coloração serossanguinolenta e coágulos de fibrina na cavidade abdominal, com hemorragias petequiais ou sufusões no peritônio parietal e visceral. O abomaso apresentava-se com acentuado aumento de volume por líquido e/ou gás com serosa friável (Fig.5) e conteúdo de coloração hemorrágica, sendo ainda observadas extensas áreas da mucosa com erosões e/ou úlceras. Dois casos (Bovinos 27 e 35) apresentaram ruptura no abomaso que variou de 5 a $10 \mathrm{~cm}$ com bordos edemaciados, avermelhados e com presença de filamentos de coágulos, caracterizando a ruptura in vivo, além do quadro macroscópico de peritonite sero-fibrinosa difusa. Em dois animais com VA (Bovinos 34 e 36) foi evidenciada a torção do abomaso no nível do piloro com parede edematosa e serosa com necrose hemorrágica. Intestinos com muco ou conteúdo hemorrágico foi um achado comum. Dois animais (Bovinos $26 \mathrm{e}$ 36) apresentaram ainda aderências entre o retículo e o diafragma, onde em um destes casos foi encontrado corpo estranho penetrante (prego metálico de $8 \mathrm{~cm}$ ), sendo também diagnosticada a síndrome da indigestão vagal do tipo II (Whitlock 1999).

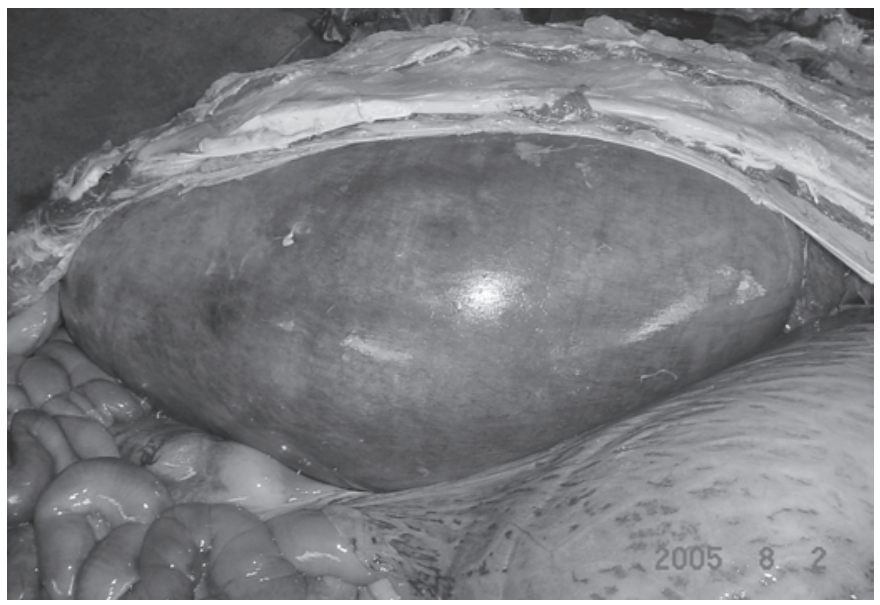

Fig.5. Abomaso do Bovino 26 com acentuado aumento de volume por líquido e gás, com serosa friável. 


\section{DISCUSSÃO}

O DA é considerado uma síndrome multifatorial (Fubini \& Divers 2008), implicando em extrema complexidade na análise dos possíveis fatores de risco envolvidos (Van Winden \& Kuiper 2003, Anderson 2009). A hipotonia/atonia abomasal é considerada o evento responsável pelo acúmulo de gás no órgão e pode ser secundária a qualquer evento que promova hipomotilidade do trato gastrintestinal (Dirksen 1961, Barros Filho \& Borges 2007). Os principais fatores que contribuem para o desenvolvimento da síndrome são: fatores alimentares, genética, desordens neuronais, doenças metabólicas e infecciosas, estresse, raça, idade e produção leiteira (Doll et al. 2009). Neste estudo, observou-se que a frequência dos fatores de tecnificação e manejo analisados foram semelhantes entre propriedades caso e controle, entretanto no item "estação do ano" notou-se significância estatística $(P<0,05)$. A estação chuvosa (março a agosto) apresentou a maior ocorrência de enfermidades, principalmente infecciosas e parasitárias, enquanto a maior casuística de DA ocorreu na estação seca (meados de setembro a fevereiro) e decorre da escassez de forragem de qualidade nesta época do ano associado ao fato de que para evitar quedas significativas na produção leiteira, os proprietários aumentam a proporção de carboidratos de fermentação rápida (concentrados) na dieta, fato correlacionado ao aumento do risco de desenvolvimento do DA (Shaver 1997, Cameron et al. 1998, Stengärde \& Pehrson 2002). Assim, são necessários estudos mais aprofundados para melhor entendimento dos principais fatores de risco envolvidos com a enfermidade em Pernambuco e no Brasil.

A literatura mundial cita maior frequência do DAE sobre o DAD e VA, contribuindo com 85 a $95,8 \%$ de todos os casos (Sattler et al. 2000, Sexton et al. 2007). Entretanto, a casuística na CBG-UFRPE apresenta marcante prevalência do DAD sobre os demais, contribuindo com $75 \%$ dos casos. Suspeita-se que a razão desta discrepância seja decorrente dos sinais clínicos mais severos desencadeados pelo DAD e VA, acarretando a procura por atendimento médico veterinário apropriado pelos proprietários. Sabe-se ainda que é rotineiro o tratamento de bovinos por leigos (proprietários, peões e práticos), com aplicação de diversos medicamentos (antibióticos, antitóxicos e soluções de cálcio). As soluções de cálcio podem ser utilizadas em quantidades suficientes para restaurar a motilidade gastrintestinal e permitir a resolução de casos leves de DA, principalmente o DAE, já que a hipocalcemia é um fator inibidor da motilidade abomasal com relação direta entre a amplitude e quantidade de contrações com os níveis plasmáticos de cálcio (Daniel 1983).

O maior número de casos de DA ocorreu em animais mestiços (Holandesa x Gir) com 24 casos (66,6\%), seguido por bovinos da raça Holandesa com 11 casos $(30,5 \%)$ e a raça Gir com um caso (2,9\%). Este fato é justificado pela predominância de raças leiteiras no Agreste e Sertão de Pernambuco, uma vez que aproximadamente $70 \%$ do leite consumido no Estado é produzido nestas regiões
(CEASA-PE 2007). Além disso, bovinos de corte apresentam risco muito menor de desenvolver DAE e VA quando comparados às raças de aptidão leiteira (Constable et al. 1992). O achado de DAE acometendo um touro da raça Gir constitui achado incomum, pois nesta raça é relatado apenas VA em um bezerro de sete meses (Câmara et al. 2009). Existe a possibilidade de que bovinos mestiços de raças zebuínas possam apresentar risco aumentado para o DAD, assim como observado nas raças leiteiras PardoSuíça e Ayrshire para o DAE, e nas raças de corte Charolais (Constable et al. 1992) e Brahman para o VA (Rousseal et al. 2000). Entretanto, não se pode descartar a hipótese de que os bovinos mestiços sejam mais acometidos por representarem a maior categoria racial atendida na rotina clínica da CBG-UFRPE (Afonso 2008).

A presença de doenças concomitantes influenciou na patogênese da enfermidade em ambas as estações, já que animais com doenças infecciosas e/ou metabólicas apresentam risco significativamente maior de desenvolver DA comparados aos controles saudáveis (Rohrbach et al. 1999, Geishauer et al. 2000, Sexton et al. 2007, Mulligan \& Doherty 2008). Qualquer doença concomitante ou condição capaz de causar hipotonia ou atonia do trato gastrintestinal pode levar ao desenvolvimento do DA. Doenças infecciosas como mastite, metrite, enterite e peritonite, assim como causas não infecciosas como hipocalcemia, hipocalemia e cetose, podem causar estase gastrintestinal e consequentemente atonia abomasal (Anderson 2009). Apesar da infecção de três bovinos com DAE pelo vírus da LEB, não existem relatos do envolvimento da doença com o DA. Na CBG-UFRPE, houve o atendimento de uma vaca Nelore de sete anos e IDGA positiva diagnosticada com DAE secundário a oclusão parcial do lúmen pilórico por linfadenopatia mesentérica (Afonso 2008).

A maioria das vacas apresentou-se acima das seis semanas (42 dias) pós-parto, enquanto sete vacas (20,5\%) possuíam gestação que variou do $2^{\circ}$ ao $8^{\circ}$ mês, sendo este último achado pouco relatado na literatura (Guimarães et al. 2007). Apesar da possibilidade do DA ocorrer esporadicamente em qualquer estágio de lactação ou gestação (Fubini \& Divers 2008), a maioria dos casos de DAE em vacas leiteiras adultas ocorre no primeiro mês de lactação (Sexton et al. 2007), período este associado com alto estresse metabólico, mudanças hormonais e alimentares (Doll et al. 2009). É relatada a ocorrência de $57 \%$ dos casos nas primeiras duas semanas pós-parto, $80 \%$ dentro do primeiro mês, e $85-91 \%$ durante as seis semanas pós-parto (Trent 2004). Em animais com DAD também há maior frequência da enfermidade no pós-parto, com $50-70 \%$ dos casos durante o primeiro mês, enquanto aproximadamente $20 \%$ das vacas não possuem correlação com o puerpério ou altas produções leiteiras (Dirksen 2005). Supõe-se que assim como em outros países, a casuística em Pernambuco decorra da interação de alguns fatores durante o período peri-parturiente, principalmente as bruscas alterações de manejo e alimentação (Shaver 1997). 
As práticas de manejo empregadas em cada sistema de criação (intensivo, semi-intensivo e extensivo) apresentam importante influência sobre o tipo de alimentação, o espaço para locomoção e exercício dos animais. O estresse causado pelas pressões que o gado leiteiro sofre para alcançar altas produções, associado aos regimes de confinamento, onde o exercício é limitado, aumenta a possibilidade de ocorrer hipomotilidade ou atonia abomasal (Radostits et al. 2007). Entretanto, algo comum em ambos os sistemas de manejo foi a oferta de moderadas a elevadas quantidades de grãos associado a dietas com, na maioria das vezes, fibras de má qualidade, sendo este um dos principais fatores associados à ocorrência do DA (Coppock et al. 1972, Shaver 1997, Stengärde \& Pearson 2002, Van Widen \& Kuiper 2003).

Dentre os alimentos volumosos ofertados destacamse a palma forrageira, o capim triturado, o bagaço de cana e a silagem de capim elefante, milho e/ou sorgo. A palma forrageira (Opuntia ficus-indica), quando utilizada como alimento único ou associada a volumosos de baixa qualidade, pode causar perda de peso, depressão na produção e no teor de gordura do leite, bem como distúrbios digestivos (diarréias e diminuição do tempo de ruminação) (Andrade et al. 2002). Outro fato importante é o uso desta cactácea muito velha na alimentação, o conteúdo da fibra eleva-se e é considerado de péssima qualidade, aumentando o risco na formação de fitobezoares (Afonso et al. 2008). Ainda acredita-se que a utilização de forragem de capim-elefante em estado avançado de maturidade e com grande concentração de lignina devido ao deficiente manejo de pastagens em diversas propriedades, associado a outras fontes de fibras, como o bagaço de cana e feno de má qualidade; propiciam fatores favoráveis ao desenvolvimento do DA. Assim como se observou a ocorrência de DA associada ao decréscimo da ingestão alimentar observada em vacas recebendo forragens fibrosas ou de qualidade inferior (Jacobsen \& Ridell 1995).

Os sinais clínicos observados são semelhantes aos citados na literatura (Trent 2004, Dirksen 2005, Van Metre et al. 2005, Barros Filho \& Borges 2007, Radostits et al. 2007, Fubini \& Divers 2008, Niehaus 2008, Anderson 2009). O principal achado no exame clínico para confirmação do diagnóstico foi a associação entre a presença de som de líquido no balotamento do flanco direito; constatação de estrutura similar a uma víscera distendida com formato de meia lua e área com som de chapinhar metálico no antímero correspondente ao lado do deslocamento. A palpação retal apresentou-se como ferramenta útil no diagnóstico do DAD, já que em $36,1 \%$ dos casos o abomaso encontrava-se palpável pelo reto, enquanto relatos anteriores citam ser possível a palpação por via retal do abomaso distendido em apenas $20 \%$ dos casos (Fubini \& Divers 2008).

As alterações hematológicas apresentaram variação de acordo com o deslocamento. Em bovinos com DAE, o achado de leucocitose por linfocitose foi comum, principalmente naqueles diagnosticados com LEB, decorrente do aumento policlonal e persistente de linfócitos B na cir- culação sanguínea, também considerada como uma forma benigna da doença (Ferrer et al. 1979). Animas com DAD e VA apresentaram, na maioria dos casos, leucocitose por neutrofilia com desvio à esquerda regenerativo, ambos associados à hiperfibrinogenemia, que são sugestivos de um processo inflamatório agudo (Zadnik 2003, Jones \& Allison 2007). Ambas as ectopias são consideradas emergências cirúrgicas devido às graves alterações circulatórias no órgão e distúrbios sistêmicos desencadeados (Van Metre et al. 2005), podendo ainda o leucograma e o fibrinogênio plasmático terem sido influenciados por doenças infecciosas concomitantes (Zadnik 2003, Jones \& Allison 2007). A presença de hemoconcentração com elevação dos valores do hematócrito e hemoglobina foram achados pouco consistentes apesar de todos os bovinos apresentarem graus de desidratação leve a grave. Os casos de discreta hipoproteinemia podem ser atribuídos à privação alimentar (Cardoso et al. 2008), enquanto os casos severos são explicados pela associação da anorexia ou hiporexia prolongada com o aumento da permeabilidade vascular ocasionada pelo processo inflamatório e transudação decorrente do aumento da pressão hidrostática e obstrução linfática oriunda da pressão exercida sobre os órgãos e vasos vizinhos pelo abomaso distendido (Jones et al. 2000).

As amostras de fluido ruminal analisadas apresentaram colorações variadas, que são explicados pela grande variedade de alimentos na dieta dos animais (Dirksen et al. 1993). O odor apresentou-se aromático, alterado e fétido, entretanto todos os animais apresentavam comprometimento da flora e fauna ruminal, fato evidenciado através da prova de redução do azul de metileno e diminuição da atividade dos protozoários, respectivamente. Tais achados são justificados pela estase ruminal, que foi mais pronunciada em casos com evolução clínica mais prolongada (Grünberg \& Constable 2009). Acredita-se que a variação de consistência do fluido ruminal e valores de pH observados são decorrentes da anorexia e consequente pouca dinâmica digestiva que ocorreu na maioria dos casos analisados, enquanto a consistência espumosa foi observada em um caso com o quadro de timpanismo espumoso concomitante. A elevação do teor de cloretos no fluido ruminal se deve ao refluxo do conteúdo abomasal rico em ácido clorídrico para os proventrículos em função do comprometimento de fluxo da ingesta provocando um decréscimo nos valores séricos deste elemento, podendo ainda acarretar um quadro sistêmico de alcalose hipoclorêmica e hipocalêmica (Taguchi 1995, Zadnik 2003, Dirksen 2005, Sahinduran \& Albay 2006, Grünberg \& Constable 2009).

Os aspectos das terapias clínicas são também valiosos adjuntos no tratamento cirúrgico, já que a cura espontânea após tratamento clínico é bastante limitada, principalmente no DAD, alcançando índices inferiores a 5\% (Buchanan et al. 1991). Entretanto, os resultados obtidos confirmam que a correção do equilíbrio hídrico-eletrolítico é fundamental para a utilização de protocolos clínicos, pois possíveis desequilíbrios de eletrólitos, principalmente a 
hipocalcemia, influenciam negativamente a restauração da motilidade gastrintestinal (Steiner 2003, Niehaus 2008). Outro adjunto terapêutico que se mostrou indispensável foi a correção dietética e a transfaunação com fluido ruminal de animais saudáveis (Rager et al. 2004).

Outro aspecto importante é o exame clínico minucioso para triagem dos casos considerados aptos para o tratamento clínico, já que esta terapia é aconselhada apenas em casos de DAE ou DAD leves, em que o paciente não apresenta distúrbios sistêmicos graves e mantém o apetite para a forragem (Radostits et al. 2007).

No tocante ao tratamento cirúrgico, a piloro-omentopexia pelo flanco direito (POFD) é uma técnica relativamente nova que associa a piloropexia com a omentopexia e permite a formação de aderência maior e mais estável, diminuindo o risco de recidiva quando comparado com a técnica de omentopexia pelo flanco direito (Baird \& Harrison 2001). A POFD vem sendo adotada por inúmeros veterinários e hospitais para correção do DAE (Bartlett et al. 1995, Baird \& Harrinson 2001) e também apresenta bons resultados no tratamento do DAD (Câmara et al. 2008). Alguns bovinos submetidos à abomasotomia apresentaram boa recuperação clínica (66,7\%), demonstrando que quando possível a exteriorização de parte do abomaso evitando a contaminação da cavidade abdominal, pode-se utilizar esta opção de esvaziamento (Fubini et al. 1991) ao invés da fixação de tubo estéril alcançando o lúmen do órgão com sutura em bolsa de tabaco (Trent 2004).

A técnica descrita apresentou resultados inferiores aos obtidos com a omentopexia pelo flanco direito (80,7-90\%) (Rohn et al. 2004, Wilson 2008) e abomasopexia paramediana ventral esquerda (100\%) (Lee et al. 2002) e direita $(83,5-95 \%)$ (Trent 2004). Entretanto, apenas um dos estudos utilizou a técnica para o tratamento de DAE e DAD (Rohn et al. 2004). Acredita-se que a menor taxa de sobrevivência observada neste estudo nos casos de DAD e VA seja decorrente da gravidade das alterações sistêmicas (Dirksen 2005, Van Metre et al. 2005) devido a demora na procura por atendimento clínico adequado, onde a evolução clínica variou de dois a 15 dias. A POFD, assim como as demais abordagens pelo flanco direito, é provavelmente a técnica mais versátil para reposicionamento e estabilização de todos os tipos de DA e possibilita o melhor acesso para as demais estruturas intra-abdominais (Trent 2004, Dirksen 2005, Niehaus 2008). Além disso, quando comparada com as demais técnicas cirúrgicas, a PFOD mostrou maior viabilidade econômica, levando em consideração o material de sutura (fio de algodão "000" e Categute cromado no1) e ausência de complicações pós-cirúrgicas (deiscência, infecções incisionais ou recidivas).

O exame clínico bem executado, associado à realização de testes simples, como a auscultação/percussão e o exame de palpação retal, são consideradas ferramentas confiáveis para o diagnóstico do DA (Richmond 1964, Smith et al. 1982, Dirksen 2005). A associação dos dados epidemiológicos, resultados dos exames hematológicos e dosagem do teor de cloretos no fluido ruminal auxiliam no diagnóstico de um distúrbio gastrintestinal obstrutivo, enquanto a laparoscopia, laparotomia exploratória e a necropsia confirmam o diagnóstico da enfermidade (Trent 2004, Dirksen 2005, Fubini \& Divers 2008, Anderson 2009).

O presente trabalho é um dos pioneiros no estudo do deslocamento do abomaso no Brasil. A análise dos possíveis fatores de risco possibilitou a identificação de uma variável (estação do ano) a ser considerada em futuras abordagens à epidemiologia da enfermidade no país, confirmando a dificuldade em analisar fatores de risco de uma síndrome multifatorial. A correlação dos achados clínicos e laboratoriais permitiu evidenciar os graves distúrbios sistêmicos, prejuízos produtivos e comprometimento do bem-estar desencadeado pela enfermidade. A abordagem clínica descrita mostrou-se eficaz no tratamento de DA moderados, enquanto a POFD apresentou-se como uma opção viável para o tratamento cirúrgico, quando realizado o diagnóstico e a intervenção o mais precocemente possível, aumentando o índice de sobrevivência pós-cirúrgica. No entanto, o prognóstico é considerado reservado em todas as condições quando há o grave comprometimento do órgão ou alterações sistêmicas importantes, e a prevenção ainda é a melhor alternativa a ser adotada. Por fim, reitera-se a necessidade de pesquisas maiores e mais aprofundadas a fim de identificar os principais fatores de risco associados ao DA no Brasil, quantificar as perdas econômicas e despertar nos produtores e médicos veterinários de campo a necessidade de implantar programas de controle e profilaxia eficientes.

\section{REFERÊNCIAS}

Afonso J.A.B. 2005. Abordagem clínica das principais enfermidades do sistema digestivo de ruminantes. Anais $2^{\circ}$ Simpósio Mineiro de Buiatria, Belo Horizonte, MG. (CD-ROM)

Afonso J.A.B. 2008. Comunicação pessoal (Clínica de Bovinos, Campus Garanhuns, Universidade Federal Rural de Pernambuco, Garanhuns, PE).

Afonso J.A.B., Pereira A.L.L., Vieira A.C., Mendonça C.L., Costa N.A. \& Souza M.I. 2008. Alterações clínicas e laboratoriais na obstrução gastrintestinal por fitobezoários em bovinos. Revta. Bras. Saúde Prod. Anim. 9(1):91-102.

Andrade D.K.B., Ferreira M.A., Véras A.S.C., Wanderley W.L., Silva L.E., Carvalho F.F.R., Alves K.S. \& Melo W.S. 2002. Digestibilidade e absorção aparentes em vacas da raça Holandesa alimentadas com palma forrageira (Opuntia ficus-indica Mill) em substituição à silagem de sorgo (Sorghum bicolor (L.) Moench). Revta Bras. Zootec. 31(5): 2088-2097.

Anderson D.E. 2009. Pathophysiology of displacement of the abomasum in cattle. p.35-40. In: Anderson D.E. \& Rings D.M. (Eds), Current Veterinary Therapy: Food animal practice. Vol.5. W.B. Saunders, Philadelphia.

Baird A.N. \& Harrison S. 2001. Surgical treatment of left displaced abomasum. Compedium 23(10):107-114.

Barros Filho I.R. \& Borges J.R.J. 2007. Deslocamento do abomaso, p.356-366. In: Riet-Correa F., Schild A.L., Lemos R.A.A. \& Borges J.R.J. (Eds), Doenças de Ruminantes e Eqüídeos. Vol.2. Gráfica e Editora Palotti, Santa Maria.

Bartlett P.C., Kopcha M., Coe P.H., Ames N.K., Ruegg P.L. \& Erskine R.J. 1995. Economic comparison of the pyloro-omentopexy vs the roll-and-toggle procedure for treatment of left displacement of the 
abomasum in dairy cattle. J. Am. Vet. Med. Assoc. 206(8):11561162.

Birgel E.H., Benesi F.J., D’Angelino J.L., Ortolani E.L. \& Matera A. 1990. Ocorrência do deslocamento de abomaso em bovinos criados no Estado de São Paulo: casuística do período de 1977 a 1986. Annals $16^{\text {th }}$ World Buiatrics Congress, Salvador, p.418-423.

Buchanan M., Cousin D.A.H., MacDonald N.M. \& Armour D. 1991. Medical treatment of right-sided dilatation of the abomasum in cows. Vet. Rec. 129(6):111-112.

Câmara A.C.L., Dantas A.C., Guimarães J.A., Afonso J.A.B., Mendonça C.L., Costa N.A. \& Souza M.I. 2007. Achados clínicos e laboratoriais de 10 casos de dilatação abomasal à direita em bovinos leiteiros resultados preliminares. Arch. Vet. Sci. 12(Supl.):114-116.

Câmara A.C.L., Afonso J.A.B., Costa N.A., Mendonça C.L. \& Souza M.I. 2008. Eficácia da piloro-omentopexia no tratamento cirúrgico do deslocamento abomasal em bovinos leiteiros no Estado de Pernambuco. Ciênc. Vet. Trop. 11(Supl.2):119. (Resumo)

Câmara A.C.L., Ximenes F.H.B., Moscardini A.R.C., Castro M.B., Godoy R.F. \& Borges J.R.J. 2009. Vólvulo abomasal em dois bezerros. Vet. Zootec. 16(3):459-464.

Cameron R.E., Dyk P.B., Herdt T.H., Kaneene J.B., Miller R., Bucholtz H.F., Liesman J.S., Vandehaar M.J. \& Emery R.S. 1998. Dry cow diet, management and energy balace as risk factors for displaced abomasum in high producing dairy herds. J. Dairy Sci. 81(1):123139.

Cardoso F.C., Esteves V.S., Oliveira S.T., Lasta C.S., Valle S.F., Campos R. \& González F.H.D. 2008. Hematological, biochemical and ruminant parameters for diagnosis of left displacement of the abomasum in dairy cows from Southern Brazil. Pesq. Agropec. Bras. 43(1):141-147.

CEASA-PE. 2007. Programa Leite de Pernambuco, Fome Zero. FoIheto, Perfil dos Lacticínios, Centro de Abastecimento Alimentar de Pernambuco, Recife. 55p.

Constable P.D., Miller G.Y., Hoffsis G.F., Hull B.L. \& Rings D.M. 1992. Risk factors for abomasal volvulus and left abomasal displacement in cattle. Am. J. Vet. Res. 53(7):1184-1192.

Coppock C.E., Noller C.H., Wolfe S.A., Callahan C.J. \& Baker J.S. 1972. Effect of forage-concentrate ratio in complete feeds fed ad libitum on feed intake prepartum and the occurrence of abomasal displacement in dairy cows. J. Dairy Sci. 55(8):783-789.

Coutinho L.T., Afonso J.A.B., Costa N.A., Mendonça C.L., Souza M.I., Pires Júnior J.B. \& Simão L.C.V. 2002. Aspectos clínicos e laboratoriais da dilatação do abomaso à direita em consequência da obstrução do piloro. Revta Bras. Med. Vet. 24(4):151-155.

Daniel R.C.W. 1983. Motility of rumen and abomasum during hypocalcaemia. Can. J. Comp. Med. 47(3):276-280.

Dirksen G. 1961. Die Erweiterung, Verlagerung und Drehung des Labmagens beim Rind. Zentralbl. Veterinärmed. 8:934-1015.

Dirksen G., Gründer H.-D. \& Stöber M. 1993. Rosenberger, Exame Clínico dos Bovinos. $3^{\underline{a}}$ ed. Guanabara Koogan, Rio de Janeiro. 419p.

Dirksen G. 2005. Enfermidades del abomaso, p.430-467. In: Dirksen G., Gründer H.-D. \& Stöber M. (Eds), Medicina Interna y Cirugía del Bovino. Vol.1. $4^{\mathrm{a}}$ ed. Intermédica, Buenos Aires.

Doll K., Sickinger M. \& Seeger T. 2009. New aspects in the pathogenesis of abomasal displacement. Vet. J. 181(2):90-96.

Ferrer J.F., Marshak R.R., Abt D.A. \& Kenyon S.J. 1979. Relationship between lymphosarcoma and persistent lymphocytosis in cattle: $A$ review. J. Am. Vet. Med. Assoc. 175(7):705-708.

Fubini S.L., Gröhn Y.T. \& Smith D.F. 1991. Right displacement of the abomasum and abomasal volvulus in dairy cows: 458 cases (19801987). J. Am. Vet. Med. Assoc. 198(3):460-464.

Fubini S. \& Divers T.J. 2008. Non infectious diseases of the gastrointestinal tract, p.130-199. In: Divers T.J. \& Peek S.M. (Eds),
Rebhun's Diseases of Dairy Cattle. $2^{\text {nd }}$ ed. Saunders Elsevier, St Louis.

Geishauser T., Leslie K. \& Duffield T. 2000. Metabolic aspects in the etiology of displaced abomasum. Vet. Clin. North Am., Food Anim. Pract. 16(2):255-265.

Grünberg W. \& Constable P.D. 2009. Function and dysfunction of the ruminant forestomach, p.12-19. In: Anderson D.E. \& Rings D.M. (Eds), Current Veterinary Therapy: Food animal practice. Vol.5. W.B. Saunders, Philadelphia

Guimarães Z.A.C.P., Saqueti C.H.C., Costa N.S., Dumont C.B.S. \& Campebell R.C. 2007. Deslocamento de abomaso para a direta no pré-parto. Arch. Vet. Sci. 12(Supl.):241-242.

Hansen L.B. 2000. Consequences of selection for milk yield from a geneticist's point of view. J. Dairy Sci. 83(5):1145-1150.

Ingvartsen K.L., Dewhurst R.J. \& Friggens N.C. 2003. On the relationship between lactational performance and health: Is it yield or metabolic imbalance that causes production diseases in dairy cattle? A position paper. Livestock Prod. Sci. 83(2-3):277-308.

Jacobsen K.L. \& Riddell M.G. 1995. Displaced abomasum and thin cows in a component-feed dairy herd. Compend. Cont. Educ. Pract. Vet. 17(Suppl.):21-27

Jain N.C. 1993. Essentials of Veterinary Hematology. Lea and Febinger, Philadelphia. 417p.

Jones T.C., Hunt R.D. \& King N.W. 2000. Distúrbios da circulação, p.167-184. In: Ibid. (Eds), Patologia Veterinária. 6ª ed. Manole, São Paulo.

Jones M.L. \& Allison R.W. 2007. Evaluation of the ruminant complete blood cell count. Vet. Clin. North Am., Food Anim. Pract. 23(3):377402.

Kramer J.W. 2000. Normal hematology of cattle, sheep and goats, p.1075-1084. In: Feldman B.F., Zinkl J.G. \& Jain N.C. (Eds), Schalm's Veterinary Hematology. $5^{\text {th }}$ ed. Lippincott Williams and Wilkins, Philadelphia.

Lee I., Yamagishi N., Oboshi K. \& Yamada H. 2002. Left paramedian abomasopexy in cattle. J. Vet. Sci. 3(1):59-60.

Mulligan F.J. \& Doherty M.L. 2008. Production diseases of the transition cow. Vet. J. 176(1):3-9.

Niehaus A.J. 2008. Surgery of the abomasum. Vet. Clin. North Am., Food Anim. Pract. 24(2):349-358.

Radostits O.M., Gay C.C., Hinchcliff K.W. \& Constable P.D. 2007. Veterinary Medicine: A textbook of the diseases of cattle, horses, sheep, pigs and goats. $10^{\text {th }}$ ed. Saunders, Edinburg. 2156p.

Rager K.D., George L.W., House J.K. \& Depeters E.J. 2004. Evaluation of rumen transfaunation after surgical correction of left-sided displacement of the abomasum in cows. J. Am. Vet. Med. Assoc. 225(6):915-920

Reichert Netto N.C. 1992. A incidência de deslocamento de abomaso em bovinos na bacia leiteira de Londrina, Paraná. Anais 22ํㅡㄴ gresso Brasileiro de Medicina Veterinária, Curitiba, p.95.

Richmond D.H. 1964. The use of percussion and auscultation as a diagnostic aid in abomasal displacement of dairy cows. Can. Vet. J. 5(1):5-7.

Rohn M., Tenhagen B.A. \& Hofmann W. 2004. Survival of dairy cows after surgery to correct abomasal displacement. 1. Clinical and laboratory parameters and overall survival. J. Vet. Med. 51(6):294299

Rohrbach B.W., Cannedy A.L., Freeman K. \& Slenning B.D. 1999. Risk factors for abomasal displacement in dairy cows. J. Am. Vet. Med. Assoc. 214(11):1660-1663.

Rousseal A.J., Cohen N.D. \& Hooper R.N. 2000. Abomasal displacement and volvulus in beef cattle: 19 cases (1988-1998). J. Am. Vet. Med. Assoc. 216(5):730-733.

Sahinduran S. \& Albay M.K. 2006. Haematological and biochemical 
profiles in right displacement of abomasum in cattle. Rev. Méd. Vét. 157(7):352-356.

Sattler N., Fecteau G., Helie P., Lapointe J.M., Chouinard L., Babkine M., Desrochers A., Couture Y. \& Dubreuil P. 2000. Etiology, forms and prognosis of gastrointestinal dysfunction resembling vagal indigestion occurring after surgical correction of right abomasal displacement. Can. Vet. J. 41(10):777-785.

Schlesselman J.D. 1982. Case Control Studies. Oxford University Press, London. 354p.

Sexton M.F., Buckley W. \& Ryan E. 2007. A study of 54 cases of left displacement of the abomasum: February to July 2005. Irish Vet. J. 60(10):605-609.

Shaver R.D. 1997. Nutritional risk factors in the etiology of left displaced abomasum in dairy cows: A review. J. Dairy Sci. 80:2449-2453.

Silva L.A.F., Silva E.B., Silva L.M., Trindade B.R., Silva O.C., Romani A.F., Fioravanti M.C.S., Souza J.C., Franco L.G. \& Garcia A.M. 2004. Causas de descarte de fêmeas bovinas leiteiras adultas. Revta Bras. Saúde Prod. Anim. 5(1):9-17.

Silva L.A.F., Coelho K.O., Machado P.F., Silva M.A.M., Moura M.I., Barbosa V.T., Barbosa M.M. \& Goulart D.S. 2008. Causas de descarte de vacas da raça holandesa confinadas em uma população de 2.083 bovinos (2000-2003). Ciênc. Anim. Bras. 9(2):383-389.

Smith D.F., Erb H.N., Kalaher K.M. \& Rebhun W.C. 1982. The identification of structures and conditions responsible for right side tympanic resonance (ping) in adult cattle. Cornell Vet. 72:180199.

Steiner A. 2003. Modifiers of gastrointestinal motility of cattle. Vet. Clin. North Am., Food Anim. Pract. 19(3):647-660.
Stengärde L.U. \& Pehrson B.G. 2002. Effects of management, feeding, and treatment on clinical and biochemical variables in cattle with displaced abomasum. Am. J. Vet. Res. 63(1):137-142.

Taguchi K. 1995. Relationship between degree of dehydration and serum electrolytes and acid-base status in cows with various abomasal disorders. J. Vet. Med. Sci. 57(2):257-260.

Trent A.M. 2004. Surgery of the abomasum, p.196-240. In: Fubini S.L. \& Ducharme N.G. (Eds), Farm Animal Surgery. W.B. Saunders, St Louis.

Van Metre D.C., Callan R.J., Holt T.M. \& Garry F.B. 2005. Abdominal emergencies in cattle. Vet. Clin. North Am., Food Anim. Pract. 21(3): 655-696.

Van Winden S.C.L. \& Kuiper R. 2003. Left displacement of the abomasum in dairy cattle: recent developments in epidemiological and etiological factors. Vet. Res. 34:47-56.

Wittek T., Sen I. \& Constable P.D. 2007. Changes in abdominal dimensions during large gestation and early lactation in HolsteinFriesian heifers and cows and their relationship to left displaced abomasum. Vet. Rec. 161:155-161.

Whitlock R. 1999. Vagal indigestion, p.517-522. In: Howard J.L. \& Smith R.A. (Eds), Current Veterinary Therapy: Food animal practice. Vol.4. W.B. Saunders, Philadelphia.

Wilson D.G. 2008. Management of abomasal displacement. Large Anim. Vet. Rounds 8(8). Disponível em: http://www.larounds.ca/crus/ laveng_10_08.pdf. Acesso em janeiro de 2009.

Zadnik T. 2003. A comparative study of the hemato-biochemical parameters between clinically healthy cows and cows with displacement of the abomasum. Acta Vet. (Beograd) 53(5/6):297-309. 